\title{
Different $O$ and $K$ serotype distributions among clinical and environmental strains of Serratia marcescens
}

\author{
HAZEL M. AUCKEN and T. L. PITT \\ Laboratory of Hospital Infection, Central Public Health Laboratory, 61 Colindale Avenue, London NW9 5HT
}

\begin{abstract}
Recent revision of the $O$ serotyping scheme for Serratia marcescens has allowed the definitive serological identification of a collection of 511 epidemiologically distinct strains in terms of both lipopolysaccharide $(\mathrm{O})$ antigens and capsular $(\mathrm{K})$ antigens. High levels of typability were achieved, $88 \%$ and $91 \%$ respectively, with only $2 \%$ failing to type with either method. In most cases, non-typability was due to a lack of antigen, i.e., the strains produced only rough LPS or were acapsular, suggesting that typability would be little improved by the discovery of additional serotypes. The distribution of the 58 O:K serotypes was very uneven, with 014:K14 accounting for $30 \%$ of the 423 clinical strains in the collection, but only $5 \%$ of the 88 non-clinical, environmental strains. Thus, the prevalence of 014:K14 strains in hospitals is not reflected in the environment. Similar conclusions were valid for $027: \mathrm{K} 14, \mathrm{O} 21: \mathrm{K} 3$ and $\mathrm{O} 21: \mathrm{K} 14$ strains, as well as those with rough lipopolysaccharide. Conversely, the proportions of O6:K3, O6:K14, O8:K14 or O28:K28 strains were significantly lower among the clinical collection than among their environmental counterparts $(12 \%$ in total rather than $65 \%)$. This suggests that O14:K14 may have a selective advantage in colonising or infecting hospitalised patients and, therefore, that the 014 and $\mathrm{K} 14$ polysaccharides themselves may contribute towards the apparent pathogenicity of these serotypes.
\end{abstract}

\section{Introduction}

Serratia marcescens is a small, gram-negative bacillus belonging to the family Enterobacteriaceae. For many years it was considered a harmless saprophyte and has frequently been isolated from plant materials [1] as well as water and soil [2]. It is a primary pathogen of insects [3,4], but rarely, if at all, of man. However, since the late $1950 \mathrm{~s}$ this organism has been increasingly identified as the cause of various hospitalacquired infections, and it is now recognised as a significant opportunist human pathogen.

In common with other nosocomial pathogens, $S$. marcescens has been the subject of many epidemiological investigations to identify possible outbreaks and common sources of infection. In the process, several typing systems have been described. One such is O serotyping, based on the detection of lipopoly-

Received 3 March 1998; accepted 25 March 1998. Corresponding author: Dr H. M. Aucken. saccharide (LPS) $\mathrm{O}$ antigens. In other gram-negative bacteria, $\mathrm{O}$ typing is a highly definitive technique, but the $S$. marcescens scheme has been plagued with cross-reactions and poor reproducibility $[5,6]$. Recent chemical and immunological studies of the LPSs of the $O$ serotype strains $[7,8]$ have allowed the development of a new $O$ typing scheme so that, for the first time, the LPS $O$ types of this species can be identified with reasonable accuracy. These studies also revealed the presence of acidic polysaccharides in the form of capsules and derived from them a complementary K-typing scheme.

Highly discriminatory systems exist for typing $S$. marcescens, generating DNA fingerprints ideal for strain comparisons, but unsuited for definitive strain typing of large populations. Serotypes, in addition to providing information on strain relationships, reveal biologically valid groups of strains that may be of value in population studies. This present study used the new $\mathrm{O}$ and $\mathrm{K}$ serotyping assays to characterise a collection of clinical and environmental strains; firstly to determine the typability and discrimination of these methods, and secondly to compare serotype distributions between the two populations. 


\section{Materials and methods}

\section{Bacterial strains}

The 423 clinical strains used in this study were also utilised in the development of the $\mathrm{O}$ and $\mathrm{K}$ typing schemes [8], having been chosen from $>3000$ isolates sent to the Central Public Health Laboratory (CPHL) between 1 Jan. 1980 and 30 June 1990 for epidemiological typing. They were selected to represent distinct strains based on their origin and the original serotyping and phage typing data $[5,6]$.

Twenty-nine strains from insects, plants and rodents were a gift from Drs P. and F. Grimont, Institut Pasteur, Paris, France. A further 42 environmental strains from insects and soil samples were received from Dr M. O'Callaghan, AgResearch (Pastoral Agricultural Research Institute), Lincoln, New Zealand. Seventeen other strains, from plants, animals and water, were obtained either from the National Collection of Type Cultures or were selected from those sent to CPHL for identification or typing.

All strains were maintained on nutrient agar or glycerol agar [9] and stored at $-20^{\circ} \mathrm{C}$ on 2-mm glass beads in glycerol $20 \% \mathrm{w} / \mathrm{v}$ broth.

\section{Species confirmation}

Tests for the differentiation of the genus Serratia, as described by Farmer et al. [10], were used to confirm the identity of the $S$. marcescens strains. The various media were inoculated from an overnight tryptone soya broth (TSB) culture and incubated at $30^{\circ} \mathrm{C}$ for up to 5 days, as recommended by Grimont et al. [2]. Isolates that produced atypical results were tested further by the CPHL Computer Identification Laboratory [11].

\section{Serotype identification}

Both $\mathrm{O}$ and $\mathrm{K}$ serotypes were determined by ELISA with adsorbed rabbit antisera as described previously. Autoclaved organisms grown in tryptone soya broth at $37^{\circ} \mathrm{C}$ overnight were used for the detection of $\mathrm{O}$ antigens, and formalinised cells grown on glycerol agar overnight at $30^{\circ} \mathrm{C}$ for the detection of $\mathrm{K}$ antigens [8]. Briefly, the ELISA plates were coated with whole-cell suspensions at an absorbance of 0.06 at $600 \mathrm{~nm}$ in carbonate buffer, before incubation with the panel of antisera. Positive reactions were detected with a goat anti-rabbit IgG-alkaline phosphatase conjugate and Sigma 104 phosphatase substrate.

Serotypes $\mathrm{O} 10$ and $\mathrm{O} 22, \mathrm{O} 16$ and $\mathrm{O} 20$, and $\mathrm{O} 18$ and O29 were merged for convenience as $\mathrm{O} 10 / 22, \mathrm{O} 16 / 20$ and $\mathrm{O} 18 / 29$, as within each pair the $\mathrm{O}$ antigens are similar both chemically and serologically and all had frequencies of $<2 \%$.

\section{SDS-PAGE and silver staining}

Crude LPS extracts were prepared, electrophoretically separated and silver-stained as described previously [12]. The resulting LPS profiles were categorised as 'rough' if only low mol. wt material was visible and 'smooth' if the typical LPS ladder pattern was present.

\section{Capsule detection}

The presence or absence of capsules was determined by the microscopic examination of cell suspensions mixed with Indian ink as a negative stain, as well as indirectly by the Cetavlon technique [7]. This method involves horizontal electrophoresis of crude capsular extracts followed by precipitation with Cetavlon, a cationic detergent that binds acidic but not neutral polysaccharides.

\section{Statistical methods}

Associations between the serotype and source were tested for statistical significance by the $\chi^{2}$ test or Fisher's exact test. The Yates' correction for noncontinuous data was applied to the $\chi^{2}$ test with one degree of freedom, while Fisher's exact test was used when one or more of the expected values was $\leqslant 0.5$.

\section{Results}

\section{Species identification}

In all, $485(95 \%)$ of the 511 strains met the criteria for identification as $S$. marcescens. The remaining 26 strains were confirmed as $S$. marcescens by extended biochemical tests. The most frequently discrepant test was non-fermentation of sorbitol, which occurred in nine strains. Negative gelatinase, lysine decarboxylase or ornithine decarboxylase test results occurred in $c$. $1 \%$ of the collection, whereas only two strains failed to produce DNAase or lipase (Table 1).

Two further tests (pigment production and adonitol fermentation), which aid the differentiation of the species within the genus Serratia, are variable characteristics in the species $S$. marcescens. Of this collection, 93 were pigmented while 51 fermented adonitol. It was notable that a much higher proportion of the environmental collection $(61 \%)$ was pigmented than the clinical collection $(9 \%)$.

\section{Source}

The 88 environmental strains originated from insects $(63 \%)$, the natural environment (plants and water, 23\%) and animals (14\%). The 423 clinical strains, i.e., those which originated from hospitals, included 114 for which a source was not known. Among the others, only the urine $(81 / 423,19 \%)$, blood $(69 / 423,16 \%)$ and respiratory tract $(61 / 423,14 \%)$ strains accounted for $>7 \%$ of the clinical collection and were therefore large enough to allow inter-source comparisons of their 
Table 1. Biochemical reactions of 511 strains of $S$. marcescens

\begin{tabular}{|c|c|c|c|c|c|c|c|}
\hline \multirow[b]{2}{*}{ Biochemical reaction } & \multicolumn{7}{|c|}{ Patterns of results given by $\mathrm{n}(\%)$ isolates } \\
\hline & $\begin{array}{c}485 \\
(94.9)\end{array}$ & $\begin{array}{c}9 \\
(1.7)\end{array}$ & $\begin{array}{c}6 \\
(1.2)\end{array}$ & $\begin{array}{c}5 \\
(1.0)\end{array}$ & $\begin{array}{c}4 \\
(0.8)\end{array}$ & $\begin{array}{c}1 \\
(0.2)\end{array}$ & $\begin{array}{c}1 \\
(0.2)\end{array}$ \\
\hline DNAase & + & + & + & + & + & + & - \\
\hline Lipase & + & + & + & + & + & - & + \\
\hline Gelatinase & + & + & + & + & - & + & + \\
\hline Lysine decarboxylase & + & + & + & - & + & + & + \\
\hline Ornithine decarboxylase & + & + & - & + & + & + & + \\
\hline Potato-like odour & - & - & - & - & - & - & - \\
\hline Prodigiosin & $\mathrm{v}$ & $\mathrm{v}$ & $\mathrm{v}$ & $\mathrm{v}$ & $\mathrm{v}$ & $\mathrm{V}$ & $\mathrm{v}$ \\
\hline \multicolumn{8}{|l|}{ Fermentation of } \\
\hline arabinose & - & - & - & - & - & - & - \\
\hline arabitol & - & - & - & - & - & - & - \\
\hline sorbitol & + & - & + & + & + & + & + \\
\hline adonitol & $\mathrm{v}$ & $\mathrm{v}$ & $\mathrm{v}$ & $\mathrm{v}$ & $\mathrm{v}$ & v & v \\
\hline dulcitol & - & - & - & - & - & - & - \\
\hline
\end{tabular}

serotype distributions. The remaining 98 clinical strains (from wound, hospital environment, peritoneal fluid, faeces, skin, eye, breast milk and cerebrospinal fluid specimens) were grouped together as 'other'. As the collection was not random, the distribution of sources could only be taken as a rough guide to the true clinical distribution. The relatively high numbers of strains from urine, blood and respiratory tract were consistent with the fact that $S$. marcescens is typically a non-enteric nosocomial pathogen. This feature of $S$. marcescens also explains the absence of statistically significant associations between clinical source and either $\mathrm{O}$ serotype or $\mathrm{K}$ serotype $(\mathrm{p}>0.05)$. Thus Fig. 1 compares the $\mathrm{O}$ and $\mathrm{K}$ serotype distributions between clinical strains as a single group and environmental strains. No significant difference was observed for the K-type distributions $(p>0.05)$, but the $O$ serotype frequencies varied markedly $(p<0.001)$ between clinical and environmental strains.

\section{Distribution of $O$ and $K$ serotypes}

Among the clinical strains, both distributions were very uneven, with $\mathrm{O} 14$ and K14 by far the most common types (Fig. 1). Frequencies $>5 \%$ were only found for three other $\mathrm{O}$ serotypes $(\mathrm{O} 21, \mathrm{O} 27$ and $\mathrm{O} 28)$ and two other K serotypes (K28 and K3). Similar percentage frequencies were found among the $\mathrm{K}$ serotypes of the environmental collection, but the $\mathrm{O}$ serotype distribution was clearly different, although still uneven. Among this collection, O6 and O8 were the most common; together they accounted for almost half of these strains, while a further $17 \%$ were $\mathrm{O} 28$. In contrast, these three serotypes accounted for only $14 \%$ of the clinical collection. Conversely, O14, the predominant clinical type, was only represented by $5 \%$ of the environmental strains. This difference in distribution of 014 strains between clinical and environmental strains was highly statistically significant, $\mathrm{p}<0.0001$. One serotype, O24, was not represented in either collection.

Typability was $88 \%$ for the O-ELISA and $91 \%$ for the
K-ELISA, but $98 \%$ overall. Of the 59 strains that failed to $\mathrm{O}$ serotype, $45(76 \%)$ were shown by SDSPAGE and silver staining to have rough LPS profiles, indicating that these strains lacked $O$ antigen. Similarly, $29(69 \%)$ of the 42 K-non-serotypable strains were found to be acapsular by Indian ink staining and the Cetavlon technique. A further difference between the $\mathrm{O}$ serotype distributions of clinical and environmental collections was that nontypable strains among the former were generally rough $(44 / 53,83 \%)$, whereas non-typable strains from the natural environment tended to have smooth LPS and may have represented undiscovered serotypes.

The original $\mathrm{O}$ serotype of 356 of the clinical strains had been obtained by agglutination with unadsorbed antisera [5]. These results were compared with the ELISA results to determine whether there was any improvement in typability and discrimination. By agglutination, 101 strains had been either non-typable or polyagglutinable giving only $72 \%$ typability, compared with $87 \%$ and $91 \%$ of these 356 strains by the $\mathrm{O}$ typing and $\mathrm{K}$ typing ELISAs respectively, and $97 \%$ when combined. Over half $(187,53 \%)$ of this smaller collection were $\mathrm{O} 14$ by agglutination, and a third of these were re-allocated to other $\mathrm{O}$ types, notably $\mathrm{O} 27$, O21, O8 and O6, leaving only $34 \%$ as O14. There were very few obvious correlations between $O$ type and original agglutination type, which seemed to correlate better with $\mathrm{K}$ type. All but six of the 187 O14-agglutinating strains were shown to be K14, while 'O3', 'O4' and 'O5' were highly correlated with K3 (18/20), K4 (12/14) and K28 (12/12), respectively.

\section{Associations between $O$ and $K$ serotype}

Table 2 shows the relationships between $\mathrm{O}$ type and $\mathrm{K}$ type which were clearly non-random, although there were only four $100 \%$ correlations: all 37 O8 strains had a $\mathrm{K} 14$ capsule, the three $\mathrm{K} 2$ strains were $\mathrm{O} 2$, the $10 \mathrm{~K} 9$ strains were $\mathrm{O} 26$, and the three $\mathrm{K} 12$ strains were all 


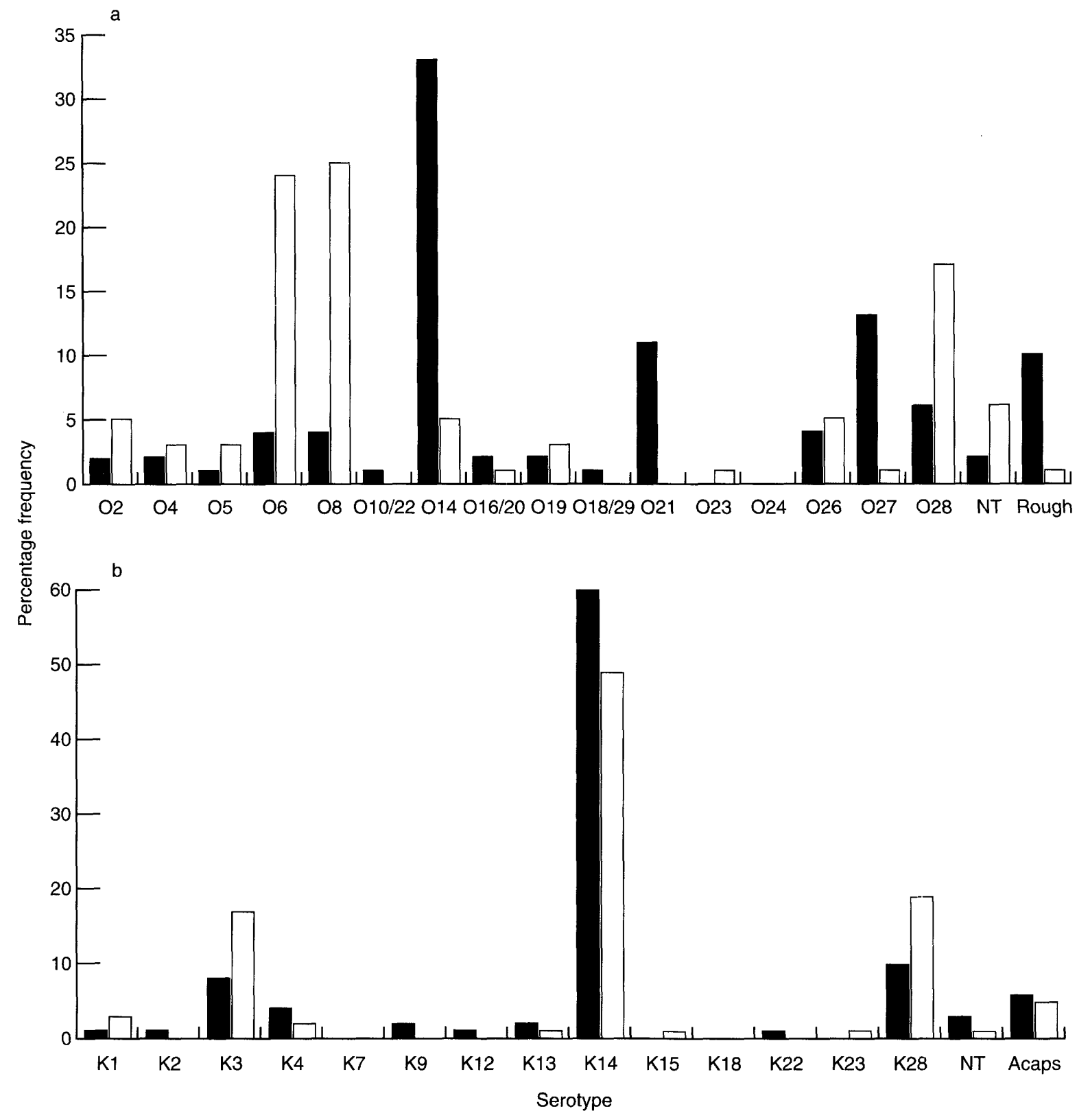

Fig. 1. Distributions of 511 clinical ( $\square$ ) and environmental ( $\square$ ) strains of S. marcescens: (a) O serotype; (b) K serotype.

O14. In total there were 58 combinations of $\mathrm{O}$ and $\mathrm{K}$ type among the 511 strains (if rough and acapsular strains are included as non-typable), with 19 combinations represented by only a single strain. Most of the O14 strains were also $\mathrm{K} 14$ while other strong correlations were $\mathrm{O} 4$ and $\mathrm{O} 27$ with $\mathrm{K} 14, \mathrm{O} 5$ and $\mathrm{O} 28$ with $\mathrm{K} 28$, and $\mathrm{O} 6$ and $\mathrm{O} 21$ with both $\mathrm{K} 3$ and K14.

Most $O$ types were found with only three or four different $\mathrm{K}$ types, although $\mathrm{O} 26$ occurred in six combinations. This number of combinations was also found among the K3, K13 and K28 strains. K14 was the most widely distributed type, as would be expected from its high frequency and its history of involvement in cross-reactions.
The distribution of $\mathrm{O}: \mathrm{K}$ serotype combinations was also significantly associated with source in that $30 \%$ of clinical strains were O14:K14 compared with only $5 \%$ of environmental strains $(\mathrm{p}<0.0001)$. A similarly skewed result was seen with $027: \mathrm{K} 14$ with frequencies of $12 \%$ and $1 \%$ respectively $(p<0.01)$. Four serotypes were found with frequencies of $10 \%$ or more among the environmental collection, namely $\mathrm{O} 6: \mathrm{K} 3$, O6:K14, O8:K14, O28:K28 which together accounted for $65 \%$ of these strains, but only $15 \%$ of the clinical strains (for each serotype, $\mathrm{p}<0.001$ ).

\section{Incident size}

The clinical strains were also classified in terms of the size of the incident from which they originated, on the 


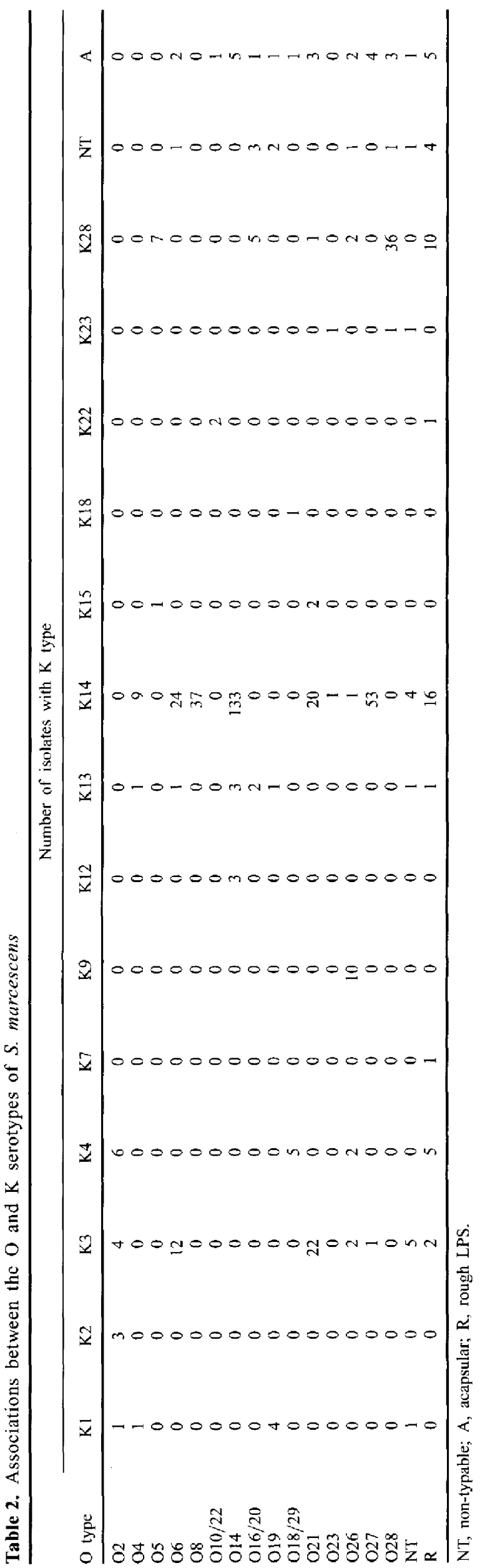


assumption that strains producing significant crossinfection may be more pathogenic in man than strains affecting single individuals. This analysis revealed that almost half $(198 / 423,47 \%)$ were apparently unique, i.e., produced sporadic infection only. This number included 10 strains from the hospital environment that did not appear to have been isolated from any patients. About a third $(134 / 423,32 \%)$ were representatives of small outbreaks (two to four patients), while $22 \%$ $(91 / 423)$ of strains were from outbreaks involving at least five patients; thus over $50 \%$ of the collection were associated with cross-infection.

The differences in distribution of sporadic and epidemic strains within each $O$ type were of only borderline statistical significance $(p=0.04)$, but there was a tendency for the more common types, such as $\mathrm{O} 14$ and $\mathrm{O} 27$, to be associated with epidemic rather than sporadic strains (c. 60:40). The converse was true of the less frequent serotypes such as O6, O8 and $\mathrm{O} 28$, which were more prevalent in the sporadic category (c. 40:60). There were no statistically significant associations among the $\mathrm{K}$ types, although it was noticeable that the acapsular group was the one with the highest proportion of sporadic strains (68\%). Rough strains were also more frequently associated with sporadic than epidemic strains $(66 \%)$.

\section{Discussion}

When used in combination, the $\mathrm{O}$ and $\mathrm{K}$ serotyping ELISAs provided a high level of typability with only $2 \%$ of the 511 strains proving to be completely non- typable. Given that, particularly among clinical strains, most non-typability was due to antigen absence (i.e., rough or acapsular strains) rather than the presence of new antigens, it is unlikely that the addition of further types to the schemes would prove of much benefit in terms of additional discrimination. This conclusion is supported, at least for the $\mathrm{O}$ serotype scheme, by the fact that there was no predominant LPS profile among the 14 smooth non-typable strains. The high level of typability contrasted favourably with the $72 \%$ typability rate of the smaller collection for which $\mathrm{O}$ agglutination results were available, and with previously published rates (Table 3) [6,13-22]. Comparison between old and new serotypes confirmed that the original $O$ typing scheme was a mixture of $\mathrm{O}$ and $\mathrm{K}$ antigens, and that the agglutination method tended to detect $\mathrm{K}$ antigens, where present. One result was an apparent reduction in frequency of the $\mathrm{O} 14$ antigen, from $53 \%$ by agglutination to $28 \%$ by ELISA, largely because the use of adsorbed antisera allowed the detection of $\mathrm{O}$ antigen independently of capsule. This revealed that the K14 capsule occurred in combination not only with $\mathrm{O6,O}$, $\mathrm{O} 14$ and $\mathrm{O} 21$ as had been described previously by Gaston et al. [23], but also with O4, O23, O26 and $\mathrm{O} 27$, as well as both capsular and acapsular K-nontypable strains.

The findings presented here indicate that, in the majority of cases, a combination of $\mathrm{O}$ and $\mathrm{K}$ serotyping should provide satisfactory discrimination of strains within hospital outbreaks. An additional typing method will be necessary to confirm strain identity among O14:K14 isolates, as this was by far the commonest type. The only other type to account

Table 3. Percentage frequency distribution of $O$ antigens among clinical isolates of $S$. marcescens

\begin{tabular}{|c|c|c|c|c|c|c|c|c|c|c|c|}
\hline \multirow{2}{*}{$\frac{\text { Criteria }}{\text { Country }}$} & \multicolumn{11}{|c|}{ Percentage frequency of $\mathrm{O}$ antigens } \\
\hline & USA & USA & USA & $\mathrm{CZ}$ & USA & USA & UK & FR & USA & UK & UK \\
\hline Year & 1957 & 1959 & 1962 & 1965 & 1970 & 1976 & 1977 & 1978 & 1980 & 1980 & 1989 \\
\hline Reference & {$[13]$} & [14] & {$[15]$} & {$[16]$} & {$[17]$} & {$[18]$} & {$[19]$} & {$[20]$} & {$[21]$} & {$[6]$} & {$[22]$} \\
\hline Number of isolates & 50 & 115 & 69 & 90 & 95 & 86 & 178 & 583 & 220 & 273 & 104 \\
\hline \multicolumn{12}{|l|}{$\mathrm{O}$ antigens } \\
\hline $\mathrm{O} 1$ & 2 & 3 & 1 & 1 & 1 & 0 & 0 & 0 & 14 & NR & 0 \\
\hline $\mathrm{O} 2$ & 24 & 12 & 3 & 1 & 26 & 11 & 1 & $<1$ & 4 & 1 & 1 \\
\hline $\mathrm{O} 3$ & 10 & 5 & 0 & 8 & 0 & 0 & 14 & 9 & $<1$ & 13 & - \\
\hline $\mathrm{O} 4$ & 12 & 9 & 9 & 9 & 20 & 5 & 1 & 3 & 20 & 8 & 22 \\
\hline O5 & 34 & 28 & 55 & 21 & 10 & 6 & 3 & 2 & 2 & 1 & 0 \\
\hline O6 & 12 & 20 & 3 & 12 & 3 & 1 & 26 & $<1$ & 0 & NR & 6 \\
\hline O7 & - & 2 & 0 & 6 & 1 & 0 & 0 & $<1$ & $<1$ & NR & - \\
\hline O8 & - & 9 & 0 & 2 & 0 & 0 & 13 & $<1$ & 0 & NR & 9 \\
\hline O9 & - & 3 & 0 & 3 & 2 & 2 & 1 & 5 & $<1$ & NR & 3 \\
\hline $\mathrm{O} 10$ & - & - & 0 & 12 & 0 & 8 & 0 & 0 & 1 & NR & 0 \\
\hline O11 & - & - & 0 & - & 19 & 3 & 0 & 0 & $<1$ & NR & - \\
\hline O12 & - & - & 0 & - & 1 & 0 & 1 & 2 & $\ll 1$ & 4 & - \\
\hline $\mathrm{O} 13$ & - & - & 12 & - & 1 & 1 & 0 & 25 & 1 & NR & - \\
\hline O14 & - & - & 10 & - & 6 & 56 & 35 & 43 & 51 & 68 & 31 \\
\hline 015 & - & - & 6 & - & 0 & 0 & 1 & $<1$ & 3 & NR & - \\
\hline O16-O20 & - & - & - & - & - & - & - & 2 & - & - & 4 \\
\hline $\mathrm{O} 21$ & - & - & - & - & - & - & - & - & - & - & 12 \\
\hline $\mathrm{O} 22-\mathrm{O} 26$ & - & - & - & - & - & - & - & - & - & - & 0 \\
\hline $\mathrm{O} 27$ & - & - & - & - & - & - & - & - & - & - & 11 \\
\hline $\mathrm{O} 28$ & - & - & - & - & - & - & - & - & - & - & 2 \\
\hline $\mathrm{PA}$ & - & - & - & 25 & - & - & - & 4 & - & 1 & 7 \\
\hline NT & 6 & 9 & 1 & - & 9 & 7 & 4 & 2 & 2 & 2 & 12 \\
\hline
\end{tabular}

CZ, Czechoslovakia; FR, France; NR, not reported; -, not tested; PA, polyagglutinable, i.e., reacted with two or more antisera; NT, nontypable. 
for $>10 \%$ of the clinical strains was $\mathrm{O} 27: \mathrm{K} 14$, while the corresponding environmental serotypes were $\mathrm{O} 6: \mathrm{K} 3$, O6:K14, O8:K14 and O28:K28. The characterisation of non-serotypable strains will also require a second typing method. In these cases it is likely that a genotypic method may prove the most satisfactory supplement. For example, ribotyping has been shown to produce results consistent with known epidemiology and biotyping [24], and to provide reliable strain discrimination when combined with biotyping or serotyping [25]. Pulsed-field gel electrophoresis of bacterial DNA digested with rare cutting enzymes also discriminates $S$. marcescens to strain level [26], as does DNA fingerprinting by the polymerase chain reaction [27]. For small investigations, the drawbacks of these methods - namely high cost, labourintensiveness and lack of definitive strain labels may well be outweighed by the advantage of good discrimination.

The uneven distribution of serotype, and in particular the predominance of O14:K14 clinical strains, suggested that these two types might be more prone to producing infections than other types. The alternative explanation, that this distribution of types simply reflects the frequencies with which these types are encountered in the environment, was clearly not supported by the serotype distribution seen among the environmental collection. Thus, the serotypes prevalent in the environment (O6:K3, O6:K14, $\mathrm{O} 8: \mathrm{K} 14$ and $\mathrm{O} 28: \mathrm{K} 28)$ are uncommon in hospitals. Furthermore, the dominant clinical serotype, O14:K14, while accounting for a third of clinical strains, represented only $5 \%$ of the environmental material. This suggests that selective pressures have been brought to bear in the clinical environment, which have favoured the survival of $\mathrm{O} 14$ strains in preference to those of other $\mathrm{O}$ types. Consequently, it can be hypothesised that either $\mathrm{O}$ antigens themselves are virulence factors influencing the pathogenicity of $S$. marcescens, or that they are closely associated with such factors. In this context it is interesting to compare the serotype distributions reported for this species since 1957 (Table 3). Direct comparisons are difficult to make because the reports used agglutination techniques that fail to differentiate $\mathrm{O}$ and $\mathrm{K}$ antigens. However, it is notable that $\mathrm{O} 14$ was not added to the serotyping scheme until the third study of $S$. marcescens serotyping, when it accounted for only $14 \%$ of isolates tested. High frequencies of O14 were not seen until the 1970s; 20 years after the first report on serotyping of this species. Furthermore, the observation that acapsular and rough strains tended to be associated with sporadic rather than epidemic strains supports the idea that the surface polysaccharides typed as $\mathrm{O}$ and $\mathrm{K}$ antigens have a role in the pathogenicity of this species.

The results of this study demonstrated that the new $O$ and $\mathrm{K}$ serotyping assays are discriminatory and no longer suffer from high levels of non-typability. Furthermore, they also demonstrate a significant difference in the distribution of serotypes between clinical and environmental strains, suggesting that the surface polysaccharides represented by these antigens may be involved in the selection of strains within the clinical setting.

\section{References}

1. Grimont PAD, Grimont F, Starr MP. Serratia species isolated from plants. Curr Microbiol 1981; 5: 317-322.

2. Grimont PAD, Grimont F. The genus Serratia. In: Starr MP, Stolp H, Truper HG, Balows A, Schlegel HG (eds) The prokaryotes: a handbook on habitats, isolation and identification of bacteria, vol 2. Berlin, Springer-Verlag. 1981: 1187-1203.

3. Grimont PAD, Grimont F. The genus Serratia. Annu Rev Microbiol 1978; 32: 221-248.

4. Grimont PAD, Grimont F, Lysenko O. Species and biotype identification of Serratia strains associated with insects. Curr Microbiol 1979; 2: 139-142.

5. Pitt TL, Erdman YJ. Serological typing of Serratia marcescens. Methods Microbiol 1984; 15: 173-211.

6. Pitt TL, Erdman YJ, Bucher C. The epidemiological type identification of Serratia marcescens from outbreaks of infection in hospitals. $J$ Hyg 1980; 84: 269-283.

7. Aucken HM, Wilkinson SG, Pitt TL. Identification of capsular antigens in Serratia marcescens. J Clin Microbiol 1997; 35: $59-63$.

8. Aucken HM, Wilkinson SG, Pitt TL. Re-evaluation the serotypes of Serratia marcescens and separation into two schemes based on lipopolysaccharide $(\mathrm{O})$ and capsular polysaccharide (K) antigens. Microbiology 1998; 144: 639-653.

9. King EO, Ward MK, Raney DE. Two simple media for the demonstration of pyocyanin and fluorescin. J Lab Clin $\mathrm{Med}$ 1954; 44: 301-307.

10. Farmer JJ, Davis BR, Hickman-Brenner FW et al. Biochemical identification of new species and biogroups of Enterobacteriaceae isolated from clinical specimens. J Clin Microbiol 1985; 21: $46-76$.

11. Holmes B, Dawson CA, Pinning CA. A revised probability matrix for the identification of Gram-negative, aerobic, rodshaped, fermentative bacteria. $J$ Gen Microbiol 1986; 132: 3113-3135

12. Aucken HM, Pitt TL. Lipopolysaccharide profile typing as a technique for the comparative typing of Gram-negative bacteria. J Clin Microbiol 1993; 31: 1286-1289.

13. Davis BR, Woodward JM. Some relationships of the somatic antigens of a group of Serratia marcescens cultures. Can $J$ Microbiol 1957; 3: 591-597.

14. Ewing WH, Davis BR, Reavis RW. Studies on the Serratia group. Atlanta, CDC Publications. 1959.

15. Ewing WH, Johnson JG, Davis BR. The occurrence of Serratia marcescens in nosocomial infections. Atlanta, CDC Publications. 1962.

16. Sedlãk J, Dlabac V, Motlikovã $M$. The taxonomy of the Serratia genus. J Hyg Epidem 1965; 9: 45-53.

17. Wilfert JN, Barrett FF, Ewing WH, Finland M, Kass $\mathrm{EH}$. Serratia marcescens: biochemical, serological and epidemiological characteristics and antibiotic susceptibility of strains isolated at Boston City Hospital. Appl Microbiol 1970; 19: $345-352$.

18. Rubin SJ, Brock S, Chamberland M, Lyons RW. Combined serotyping and biotyping of Serratia marcescens. $J$ Clin Microbiol 1976; 3: 582-585.

19. Anderhub B, Pitt TL, Erdman YJ, Willcox WR. A comparison of typing methods for Serratia marcescens. J Hyg 1977; 79: 89-102.

20. Le Minor S, Pigache F. [Antigenic study of "Serratia marcescens" isolated in France. II. Characterisation of $\mathrm{O}$ antigens and description of 5 new $O$ factors, occurrence of serotypes and labelling of new $\mathrm{H}$ factors.] Étude antigénique de souches de Serratia marcescens isolées en France. II. Caractérisation des antigènes $\mathrm{O}$ et individualisation de 5 nouveaux facteurs, fréquence de sérotypes et désignation des 
nouveaux facteurs H. Ann Microbiol 1978; 129B: 407-423.

21. Young VM, Moody MR, Morris MJ. Distribution of Serratia marcescens serotypes in cancer patients. $J$ Med Microbiol 1980; 13: 333-339.

22. Gaston MA, Pitt TL. Improved O-serotyping method for Serratia marcescens. J Clin Microbiol 1989; 27: 2702-2705.

23. Gaston MA, Duff PS, Pitt TL. Lipopolysaccharide heterogeneity in strains of Serratia marcescens agglutinated by 014 antiserum. Curr Microbiol 1988; 17: 27-31.

24. Bale M, Sanford M, Hollis R, Pfaller MA. Application of a biotyping system and DNA restriction fragment analysis to the study of Serratia marcescens from hospitalized patients. Diagn Microbiol Infect Dis 1993; 16: 1-7.
25. Alonso R, Aucken HM, Perez-Diaz JC, Cookson BD, Baquero F, Pitt TL. Comparison of serotype, biotype and bacteriocin type with rDNA RFLP patterns for the type identification of Serratia marcescens. Epidemiol Infect 1993; 111: 99-107.

26. Traub WH, Eiden A, Leonhard B, Bauer D. Typing of nosocomial strains of Serratia marcescens: comparison of restriction enzyme cleaved genomic DNA fragment (PFGE) analysis with bacteriocin typing, biochemical profiles and serotyping. Zentralbl Bakteriol 1996; 284: 93-106.

27. Debast SB, Melchers WJG, Voss A, Hoogkamp-Korstanje JAA Meis JFGM. Epidemiological survey of an outbreak of multiresistant Serratia marcescens by PCR-fingerprinting. Infection 1995; 23: 267-271. 